\title{
Partial Edentulousness in Patients Visiting the Dental Out-Patient Department of Gandaki Medical College, Pokhara, Nepal
}

\author{
Bhandari $\mathbf{A}^{{ }^{*}}$, Manandhar $\mathbf{A}^{2}$, Manandhar $\mathbf{P}^{1}$ \\ 'Lecturer, Dept. of Prosthodontics, ${ }^{2}$ Lecturer, Dept. of Conservative Dentistry and Endodontics, \\ College of Dental Surgery, Gandaki Medical College \& Teaching Hospital, Pokhara, Nepal
}

\section{Keywords}

Dental caries, Kennedy's classification,

Partial edentulism.

\section{Corresponding author}

*Dr. Arjun Bhandari

Lecturer, Department of Prosthodontics, College of Dental Surgery

Gandaki Medical College, Pokhara, Nepal

Email: arjunnbhandari@gmail.com

\begin{abstract}
Introduction: Partial edentulousness is a dental arch in which one or more but not all natural teeth are missing due to dental caries, periodontal problems, trauma etc. It causes difficulty in chewing food, alteration of speech and unpleasant esthetics which adversely affect the general health and quality of life.
\end{abstract}

Methods: This study was conducted in the Department of Prosthodontics, College of Dental Surgery, Gandaki Medical College, Pokhara from November 2017 to March 2018. All patients above the age of 15 years presenting with partial loss of dentition and willing to give informed consent were included in the study. Data regarding age, gender, missing teeth, cause of permanent tooth loss and denture status were collected from 342 patients.

Results: The most common cause of permanent tooth loss was dental caries $(58.2 \%)$ followed by periodontal (18.1\%), dental caries and periodontal $(9.4 \%)$, trauma (7.9\%), dental caries and trauma $(2.9 \%)$, periodontal and trauma (2.3\%) and others (1.2\%).The distribution of partially edentulous areas in maxillary arch (35.7\%), mandibular arch (45.9\%) and both arches (18.4\%).The most common type of partial edentulism was found to be Kennedy's class III followed by class II, class I and class IV in both the arches.

Conclusion: The most common cause of permanent tooth loss was dental caries. Mandibular arch was more affected than the maxillary arch. The most common type of partial edentulism was Kennedy's class III.

\section{INTRODUCTION}

Partial edentulousness is a dental arch in which one or more but not all natural teeth are missing. Edentulism can occur due to dental caries, periodontal problems, poor oral hygiene, trauma, pulpal, periradicular disease, orthodontic and prosthodontic indications and some systemic factors. ${ }^{1,2}$ It causes difficulty in chewing food, alteration of speech and unpleasant esthetics which adversely affect the general health and quality of life. ${ }^{3,4}$
For prevention and treatment of oral diseases, information is required about the cause of permanent tooth loss. The prevalence and patterns of tooth loss have been studied to a certain extent in other countries, but a few studies have been carried out in our country. A simple estimation of the proportion of partially edentulism is a rough indication of the prevalence of dental diseases and the success or failure of dental care. This forms a background for the assessment of treatment needs. 
This study aims to identify the causes of permanent tooth loss and determine the pattern of partial edentulousness based on Kennedy's classification in patients visiting the dental OPD of Gandaki Medical College \& Teaching Hospital, Pokhara, Nepal.

\section{MATERIALS AND METHODS}

This cross sectional study was carried out at Department of Prosthodontics, College of Dental Surgery, Gandaki Medical College \& Teaching Hospital, Pokhara, Nepal. After the approval from institutional review committee, study was conducted among patients visited dental outpatient department from November 2017 to March 2018. Consecutive sampling technique was followed, and sample size was calculated as 342 . The written informed consent was acquired before enrolling them to study.

The inclusion criteria were: aged between 15 years and 80 years, having partially edentulous region and those willing to give consent.

The exclusion criteria involved the patients who had completely edentulous or only missed maxillary and mandibular third molars. A brief history was taken and recorded in the case record sheet followed by oral examination using the Kennedy's classification by principal investigator.

\section{Kennedy's classification:}

Class-I: Bilateral edentulous area located posterior to the remaining natural teeth.

Class-II: Unilateral edentulous area located posterior to the remaining natural teeth.

Class-III: A unilateral edentulous area with natural teeth both anterior and posterior to it.

Class-IV: Single but bilateral edentulous area located anterior to the remaining natural teeth.

The findings were entered in work proforma and the data were entered into Microsoft 2007 Excel sheet. The descriptive statistical analysis was done using SPSS version 15 by age, gender, cause of permanent tooth loss, status of denture wearer, pattern of partial edentulism.

\section{RESULTS}

Out of 342 study population 147 (43\%) were males and
195 (57\%) were females with the age ranged between 15 80 years (Table 1). The most common cause of permanent tooth loss was dental caries (58.2\%) followed by periodontal (18.1\%), dental caries and periodontal (9.4\%), trauma (7.9\%), dental caries and trauma (2.9\%), periodontal and trauma (2.3\%) and others (1.2\%). Mandibular was $18.4 \%$ of the study population had partial edentulism on both arches, while $35.7 \%$ had partial edentulism on the maxillary arch only and $45.9 \%$ on the mandibular arch only (Table 3 ). In the maxillary arch, Kennedy's class III (24.9\%), was the most common pattern of partial edentulism followed by class II (10.5\%), class I (10.2\%), class IV (8.5\%) Similarly in the mandibular arch, Kennedy's class III (34.5\%) was the most common pattern of partial edentulism followed by class II (14.6\%), class I (9.4\%), and class IV (5.8\%). (Table 4). Only $21.8 \%$ of the study population had replace their missing teeth (Table 5).

Table 1: Age and gender Distribution

\begin{tabular}{ccc}
\hline \multirow{2}{*}{ Age range } & \multicolumn{2}{c}{ Gender distribution } \\
\cline { 2 - 3 } & Males n(\%) & Females n(\%) \\
$15-80$ years & $147(43 \%)$ & $195(57 \%)$ \\
\hline
\end{tabular}

Table 2: Causes of permanent tooth loss

\begin{tabular}{clc}
\hline S.No & Causes of permanent tooth loss & Number (Percentage) \\
1 & Dental caries & $199(58.2 \%)$ \\
2 & Periodontal & $62(18.1 \%)$ \\
3 & Trauma & $27(7.9 \%)$ \\
4 & Dental caries and periodontal & $32(9.4 \%)$ \\
5 & Dental caries and trauma & $10(2.9 \%)$ \\
6 & Periodontal and trauma & $8(2.3 \%)$ \\
7 & Others & $4(1.2 \%)$ \\
\hline
\end{tabular}

Table 3: Arch wise distribution of partial edentulism

\begin{tabular}{ccc}
\hline Arch & Number & Percentage \\
Maxillary only & 122 & $35.7 \%$ \\
Mandibular only & 157 & $45.9 \%$ \\
Both arches & 63 & $18.4 \%$ \\
Total & 342 & 100 \\
\hline
\end{tabular}

Table 4: Distribution of Kennedy's classification in maxillary and mandibular arch

\begin{tabular}{ccc}
\hline Kennedy's Class & Maxillary Arch n(\%) & Mandibular Arch n(\%) \\
Class I & $35(10.2 \%)$ & $32(9.4 \%)$ \\
Class II & $36(10.5 \%)$ & $50(14.6 \%)$ \\
Class III & $85(24.9 \%)$ & $118(34.5 \%)$ \\
Class IV & $29(8.5 \%)$ & $20(5.8 \%)$ \\
\hline
\end{tabular}


Table 5: Distribution of denture wearer and non denture wearer

\begin{tabular}{cc}
\hline Denture Wearer n(\%) & Non Denture Wearer n(\%) \\
$75(21.8 \%)$ & $267(78.2 \%)$ \\
\hline
\end{tabular}

\section{DISCUSSION}

In our study, we found that partial edentulism was more common in females than in males, which is consistent with the study carried out by Naveed H et $\mathrm{al}^{4}$, Sapkota B et $\mathrm{al}^{5}$, and Patel JY et al. ${ }^{6}$ However, some earlier studies showed more males being edentulous than females., This contradiction may be in part due to more females visiting the dental hospital and could also be attributed to the different socio-economic background and malhabits like smoking and consumption of high sugarcontaining diets among males. The most common cause of permanent tooth loss was found to be dental caries (58.2\%) followed by periodontal disease (18.1\%) which is in agreement with the findings of studies carried out by Muneeb A et al, ${ }^{9}$ Akinboboye B et al. ${ }^{10}$ The poor oral hygiene and inaccessibility for proper cleaning could be the possible reason which ultimately leads to dental caries and periodontal problems for tooth extraction.

In our study, Mandibular arch was affected more than the maxillary arch which is consistent with findings of other studies. ${ }^{4,6}$ The most common type of edentulism was Kennedy's class III both in maxilla and mandible which is in agreement with the various studies conducted by Naveed et al, ${ }^{4}$ Sapkota et al, ${ }^{5}$ Patel et $a l,{ }^{6}$ Muneeb et al, ${ }^{9}$ Bharathi $\mathrm{M}$ et al. ${ }^{11}$ This could be due to the fact that the first molar is the first permanent tooth to erupt into the oral cavity, having a higher caries percentage and a higher chance of the tooth being extracted. The second most common type of edentulism was Kennedy's class I and least prevalent is class IV both in maxilla and mandible which is in agreement with various studies conducted by Patel et al, ${ }^{6}$ Bharathi et al ${ }^{11}$ and Charyeva et al. ${ }^{12}$ However Kennedy's class I was the least common in the study conducted by Munneeb et al. ${ }^{9}$

In our study, $21.8 \%$ of the study population had already replaced their missing teeth. Of the various classes of partial edentulism patients with class IV situation got their teeth replaced which could be attributed to esthetic reasons. This was followed by class I and II; the main reason could be for masticatory purposes. However, persons with class III had the less percentage of replacement, which could be because they had an option of getting their teeth replaced with a fixed partial denture or an implant which might have been beyond their affordability.

\section{CONCLUSION}

The most common cause of permanent tooth loss was dental caries. Mandibular arch was more affected than the maxillary arch. The most common type of partial edentulism was Kennedy's class III and least common was Kennedy's class IV in both the arches.

\section{Acknowledgement}

I would like to acknowledge Prof. Dr. Ishwori Sharma Poudel for his help during the statistical analysis of this study.

\section{REFRENCES}

1. Bratu E, Bratu D, Antonie S. Classification system for partial edentulism. J Oral Health Dent. 2007;4:50-5.

2. D'Souza KM, Aras M. Association between sociodemographic variables and partial edentulism in the Goan population: An epidemiological study in India. Indian J Dent Res. 2014;25:434-8.

3. Batista MJ, Lawrence HP, de Sousa MLR. Impact of tooth loss related to number and position on oral health quality of life among adults. Health Qual Life. 2014;12:165.

4. Naveed H, Aziz MS, Hassan A, Khan W, Azad AA. Patterns of partial edentulism among armed forces personnel reporting at Armed Forces Institute of Dentistry Pakistan. Pak Oral Dent J. 2011;31:217-21.

5. Sapkota B, Adhikari B, Upadhaya C. A Study of assessment of partial edentulous patients based on Kennedy's classification at Dhulikhel Hospital, Kathmandu University Hospital. Kathmandu Univ Med J. 2013;11(4):325-7.

6. Patel JY, Vohra MY, Hussain JM. Assessment of partially edentulous patients based on Kennedy's classification and its relation with gender predilection. Int J Sci Study. 2014; 2:32-6. 
7. Suominen-Taipale AL, Alalen P, Helenius H, Nordblad A, Uutela A. Edentulism among Finnish adults of working age, 1978-1997. Community Dent Oral Epidemiol. 1999 October;27(5):353-65.

8. Hoover JN, Mc Dermott RE. Edentulousness in patient attending a University dental clinic. J Can Dent. Assoc. 1989 March;55(2):139-40.

9. Muneeb A, Mohsin B, Jamil B. Causes and pattern of partial edentulism / exodontia and its association with age and gender : Semi rural population, Baqai dental college, Karachi, Pakistan. Int Dent J Students' Res. 2013;1:13-8.

10. Akinboboye B,Azodo C, Soroye M. Partial edentulism and unmet prosthetic needs amongst young adult Nigeria. Odontostomatol Trop. 2014;37:47-52.

11. Bharathi M, Babu KRM, Reddy G, Gupta N, Misuria A, Vinod V. Partial edentulism based on Kennedy's classification: An epidemiological study. J Contemp Dent Pract. 2014;15:229-31.

12. Charyeva 00, Altynbekov KD, Nysanova BZ. Kennedy classification and treatment options: A study of partially edentulous patients being treated in a specialized prosthetic clinic. J Prosthodont. 2012;21:177-80. 